\title{
Capacity, population aging and professionalism
}

$\mathrm{T}$ he role of physicians in relieving suffering and improving function is only part of the physicianpatient relationship. Acting with beneficence (and doing no harm) must be done in partnership with patients. Physicians seek partnership because they recognize patients' autonomy and because, without partnership, they risk paternalism. We can easily accept the primacy of autonomy when articulate patients actively engage us, but it becomes trickier when their capacity is compromised. Our heavy reliance on respecting autonomy through legal consent procedures has obscured our obligation to not treat people using practices, and in physical environments, that undermine their capacity.

Conceptually, capacity is graded and changeable. Procedurally, this requires a means of determining capacity, reassessing capacity and providing for substitute decisionmaking. In everyday medical practice, especially in hospitals, ${ }^{1}$ the pressure to proceed, the complexity of patients' needs and the reliance on assent - from, one notes, a largely assenting population - mean that respect for autonomy is often post hoc, notional and symbolic.

Two reasons motivate me to talk about how the autonomy of frail elderly people (those who have multiple, interacting medical and social problems) is commonly ignored in the acute care hospital setting. Many frail elderly people are evidently competent when they are not ill and when they live with structured routines in familiar environments. But when they fall ill and come to hospital, their capacity quickly can be compromised, even in the absence of frank delirium. Because frail elderly people are disproportionately heavy consumers of acute health care, we need to find either a way to formalize and facilitate their giving consent to care or a better understanding of whether what we do in usual care can be justified ethically. We should also look carefully at what we do now, because unless we separate actual practice from the rhetoric of idealized practice, we have no way to distinguish good practice from bad: each instead is condemned by its failure to ideally respect autonomy.

I am not advocating for more informed consent, although others see this to be both desirable and feasible. ${ }^{2}$ I do think we need to hold physicians and hospitals accountable, not because they have assumed consent instead of applying procedures to obtain it, but rather because they have assumed cono sent to do things that offer little hope of alleviating suffering, improving function or averting avoidable death. Among frail elderly people, I see more injury from inadequate attention to our obligations not to do harm and to do good than from our failure to obtain consent. This is most obvious in the fully consented elderly patient whose hernia, heart or hip has been healed after elective surgery but whose cognition and func- tion have been irretrievably harmed and whose frailty was inadequately understood preoperatively.

Consequently, I believe that we must investigate how the autonomy of frail elderly patients depends on their environment and on their illness state. With this knowledge, we will be able to respect their autonomy by designing environments and processes of care (including the routine assessment of frailty) that would enhance capacity and not compromise it. It could extend to innovations that would make it easier for us to provide care in patients' homes, where their autonomy is less likely to be compromised. ${ }^{3}$

We also need a better understanding of how physicians should relate to frail elderly patients whose competence is recognizably uncertain. Is beneficence/nonmalfeasance just the old paternalism? Can physicians find a way to work ethically with frail patients without the patients having to assert autonomy or the physicians ignoring diminished capacity? One answer might be a renewed professionalism, the recognition that physicians owe a duty to use their knowledge, clinical skills and judgment for their patients' benefit. A group in the United Kingdom has recommended that each doctor reflect on the definition and discretion of medical professionalism in order to see how it is expressed in his or her daily practice. ${ }^{4}$ Might this yield a theory of professionalism more coincident with the limits to autonomy of our frail patients? If so, it would allow good practice to be distinguished from bad practice. ${ }^{5,6}$

That professionalism is hard won has been known since Hippocrates: "Life is short, the Art long; the occasion fleeting; experience fallacious, and judgment difficult." If we are to provide better care for our frail elderly patients, we must carefully examine and enhance how the physician-patient relationship can be based on a well-founded trust.

\section{Kenneth Rockwood}

Professor of Medicine (Geriatric Medicine and Neurology) Dalhousie University

Halifax, NS

This article has been peer-reviewed.

\section{REFERENCES}

I. Raymont V, Bingley W, Buchanan A, et al. Prevalence of mental incapacity in medical inpatients and associated risk factors: cross-sectional study. Lancet 2004;364:I42I-7. 2. Karlawish JH. Competency in the age of assessment. Lancet 2004;364:1383-4.

3. Caplan GA, Coconis J, Board N, et al. Does home treatment affect delirium? A randomised controlled trial of rehabilitation of elderly and care at home or usual treatment (the REACH-OUT trial). Age Ageing 2006;35:53-6o.

4. Tallis RC. Doctors in society: medical professionalism in a changing world. Clin Med 2006;6:7-I2.

5. Tauber AI. Patient autonomy and the ethics of responsibility. Cambridge (MA): MIT Press; 2005.

6. Agich GJ. Dependence and autonomy in old age: an ethical framework for longterm care. Cambridge (UK): Cambridge University Press; 2003. 